\title{
Reversal of Haloperidol-Induced Orofacial Dyskinesia and Neuroinflammation by Isoflavones
}

\author{
Natália Fernandes Mezzomo \\ Universidade Franciscana \\ Izaviani da Silva Schmitz \\ Universidade Franciscana \\ Valtieri Bortoluzzi de Lima \\ Universidade Franciscana
}

\section{Gilson Pires Dorneles}

Universidade Federal de Ciências da Saúde de Porto Alegre: Universidade Federal de Ciencias da Saude de Porto Alegre

\section{Larissa Finger Schaffer \\ Universidade Franciscana}

\section{Carina Rodrigues Boeck}

Universidade Franciscana

\section{Pedro Roosevelt Torres Romao}

Universidade Federal de Ciências da Saúde de Porto Alegre: Universidade Federal de Ciencias da Saude de Porto Alegre

\section{Luis Ricardo Peroza ( $\Delta$ perozalr@gmail.com )}

Universidade Franciscana https://orcid.org/0000-0002-5361-0043

\section{Research Article}

Keywords: Antipsychotics, Tardive dyskinesia, Isoflavones, Neuroinflammation.

Posted Date: July 30th, 2021

DOl: https://doi.org/10.21203/rs.3.rs-735295/v1

License: (c) (i) This work is licensed under a Creative Commons Attribution 4.0 International License. Read Full License

Version of Record: A version of this preprint was published at Molecular Biology Reports on December 1st, 2021. See the published version at https://doi.org/10.1007/s11033-021-07003-7. 


\section{Abstract}

Schizophrenia is a serious mental illness, and its pharmacological treatment consists in the administration of antipsychotics, such as haloperidol. However, treatment with haloperidol often causes extrapyramidal motor disorders such as tardive dyskinesia (TD). TD is a movement disorder characterized by involuntary movements, which can be studied in animals. So far, there is no effective treatment for TD and alternatives have been sought. Thus, the objective was to evaluate the possible protective effect of isoflavones against the induction of involuntary movements induced by haloperidol in an animal model. Male Wistars rats were treated with haloperidol $(1 \mathrm{mg} / \mathrm{kg} / \mathrm{day})$ and/or isoflavones (80 $\mathrm{mg} / \mathrm{kg}$ ) for 28 days. Rats were submitted to behavioral evaluation to quantify vacuous chewing movements (VCM) and the locomotor activity. In addition, the levels of pro-inflammatory cytokines were measured in the striatum. Haloperidol treatment reduced the locomotor activity and increased the number of VCM in rats. Co-treatment with isoflavones was able to reverse hypolocomotion and reduce the number of VCM to the levels of the control group. Besides, haloperidol caused significant increase in the proinflammatory cytokines (interleukin-1 $\beta$ :IL-1 $\beta$, tumor necrosis factor-a:TNF-a and IL- 6 and the cotreatment with isoflavones was able to reduce the levels of IL-1 $\beta$ and TNF- $\alpha$, but not IL- 6 . It is believed that the beneficial effect found with this treatment is related to their anti-inflammatory potential and also to the action on estrogen receptors (based on findings in the scientific literature). Finally, further studies are needed to elucidate the mechanisms of isoflavones in reducing motor disorders induced by antipsychotic.

\section{Introduction}

Schizophrenia is a serious mental illness, with a prevalence of approximately $1 \%$ in the world population (ljaz et al. 2018). The clinical manifestations of this disease include behavioral distortions, verbal communication, perceptions and self-awareness, which can significantly affect the individual's educational and work performance (Bhugra 2005). The etiology of the disease is still uncertain, the hypothesis of dopaminergic hyperfunction is one of the most accepted (Nardi et al. 2015).

The pharmacological treatment of schizophrenia consists in the administration of antipsychotics, which are divided into first generation (eg, haloperidol), second generation (eg: risperidone) and more recently third generation (aripriprazole) (Brown et al. 2012). One of the most potent and most used antipsychotics, haloperidol, acts by preferentially antagonizing the dopamine receptor of subtype D2, reducing dopamine levels in different dopaminergic pathways and being effective mainly against positive symptoms of schizophrenia, such as hallucinations. However, treatment with haloperidol often causes extrapyramidal motor disorders (parkinsonism, akathisia, dystonia and tardive dyskinesia) (Amato et al. 2016).

Tardive dyskinesia (TD) is a movement disorder more commonly observed in patients with psychotic disorders treated with antipsychotic dopamine blockers (Witter et al. 2017). In animals, this disorder is known as orofacial dyskinesia (OD) (Casey 1993; Tsai et al. 1998). A peculiar characteristic of TD is the persistence of the symptom after withdrawal of the drug. It becomes irreversible, indicating that 
antipsychotics, such as haloperidol, produce changes in brain function that are not related to the presence of the drug (Glazer 2000; Liu et al. 2012). Many of the side effects related to the use of these antipsychotics have been studied and several hypotheses have been proposed, such as oxidative stress (Burger et al. 2004), and neuroinflammation (Bishnoi et al. 2008; Peroza et al. 2016). However, the mechanisms related to the pathophysiology of TD or OD still remain uncertain.

Neural degeneration is one an important hypotheses for TD (Lohr, 1991), which could be caused by dysregulation of cytokines and chemokines in central nervous system, leading to neuroinflammation (Glass et al. 2010; Smith et al. 2012), as well as are important contributors to the development and progression of the neurodegenerative processes (Frank-Cannon et al. 2009). Furthermore, the overproduction and exaggerated release of cytokines is associated with neuronal dysfunctions, as described in psychiatric disorders (Glass et al. 2010).

In this context, previous studies have demonstrated a protective role of antioxidants against OD induced in rats, for example Bauhinia forficate which has been shown to have antioxidant capacity in previous studies (Burger et al. 2004; Peroza et al. 2013). Isoflavones are phenolic compounds present in high concentration in legumes, such as soybeans (Cook and Samman 1996), being known as phytoestrogens due to their ability to bind to estrogen receptors in vivo (Dixon 2004), Many of the beneficial effects of isoflavones are believed to be partly attributed to their antioxidant capacity (Wei et al. 1993). and have benefits against neurodegenerative diseases (Liu et al. 2010). A recent study of our research group showed that soy isoflavones have neuroprotective activity in vitro and are also able to inhibit isoforms $\mathrm{A}$ and $B$ of the monoamine oxidase enzyme, which could modulate the levels of monoaminergic neurotransmitters within the central nervous system (Da Silva Schmitz et al. 2019).

Thus, the aim of the present study was to evaluate the possible protective effect of isoflavones against the induction of involuntary movements induced by antipsychotic medication in rats and the participation of neuroinflammation in this process.

\section{Methods}

\section{Animals}

For this study, male Wistar rats ( \pm 2 months), weighing between 200 and $250 \mathrm{~g}$, were used. The animals remained in the bioterium of the Universidade Franciscana (UFN) with free access to food and water, controlled temperature $\left(22 \pm 1^{\circ} \mathrm{C}\right)$ and 12 hours light/dark cycle. The experimental protocol was approved by the Animal Use Ethics Commission (CEUA) of the Franciscan University (UFN), under number 05/2017.

\section{Drugs}

Haloperidol decanoate (Haldol $\left.{ }^{\circledR}\right)$ was obtained from a commercial pharmacy, while isoflavone powder, in a manipulation pharmacy in the city of Santa Maria - RS. The certificate of analysis of the isoflavone 
powder carried out by the company Galena Química e Farmacêutica Ltda (Campinas / SP) shows the presence of: Glicitin $(0.78 \%)$, Genistin $(0.37 \%)$, Genistein $(0.21 \%)$, Daidzein $(38.81 \%)$, Daidzin $(0.20 \%)$, glycitein (0.27) - totaling $40.64 \%$ of isoflavones.

\section{Animal Treatment}

Thirty two rats were divided into 4 groups $(\mathrm{N}=8)$ : control, isoflavones, haloperidol and haloperidol + isoflavones. The isoflavone powder was dissolved in saline $(80 \mathrm{mg} / \mathrm{kg})$ and administered daily by gavage for 28 days (Ding et al. 2011), for the isoflavones and haloperidol + isoflavones groups. The saline vehicle was also administered by gavage in the control and haloperidol groups. The administration of haloperidol for haloperidol and haloperidol + isoflavones groups, occurred only on the first day of treatment, through the intramuscular pathway, at a dose of $38 \mathrm{mg} / \mathrm{kg}$, which is equivalent to 1 $\mathrm{mg} / \mathrm{kg} /$ day of unconjugated haloperidol (Fachinetto et al. 2007), as its formulation is slow-release and has been present at stable levels for 28 days. Vegetable oil (haloperidol decanoate vehicle) was also administered only once to the control and isoflavone groups.

\section{Quantification Of VCM}

The behavioral assessment of VCM was performed before treatment with haloperidol and/or isoflavones (baseline evaluation), as previously described by (Fachinetto et al. 2007). The evaluation of the effects of treatments on behavior were evaluated $24 \mathrm{~h}$ after the last administration of isoflavones (at 29 days). To quantify the occurrence of $\mathrm{VCM}$, the rats were individually placed in mirrored boxes $(20 \times 20 \times 19 \mathrm{~cm})$. VCM are defined as the opening of the mouth in the vertical plane. After 6 minutes of adaptation in the mirrored box, the behavioral parameter of diskynesia orofacial were continuously evaluated for 6 minutes.

\section{Open Field Test}

To analyze spontaneous changes in locomotor activity caused by treatment with haloperidol and /or isoflavones, the rats were placed individually in a box $(40 \times 40 \times 30 \mathrm{~cm})$ with floors divided into quadrants, as described by Broadhurst (1960). The number of crossings was measured during 5 minutes, as indicators of locomotor activity.

\section{Determination of cytokine levels}

After the last behavioral analysis, the animals were killed by decapitation and the striatum was dissected for cytokine dosages. The levels of TNF- $a$, interleukin- 1 beta (IL-1 $\beta$ ) and IL- 6 were quantified by EnzymeLinked Immunosorbent Assay (ELISA) using an appropriate commercial kit (Peprotech Inc., EUA) according to the manufacturer's instructions. The detection limits of each cytokine were IL-1 $\beta, 10.5-800$ $\mathrm{pg} / \mathrm{mL}$ with sensitivity of $4.8 \mathrm{pg} / \mathrm{mL} ; \mathrm{IL}-6,5.6-500 \mathrm{pg} / \mathrm{mL}$ with sensitivity of $2.1 \mathrm{pg} / \mathrm{mL}$; and TNF-a, 7.9$700 \mathrm{pg} / \mathrm{mL}$ with sensitivity of $7.21 \mathrm{pg} / \mathrm{mL}$.

\section{Statistical Analysis}


Data were expressed as mean \pm standard error of the mean (SEM) They were analyzed by one-way analysis of variance (ONE WAY ANOVA) followed by the Newman-Keuls test. The correlations between the number of VCM and cytokine levels in the striatum were determined by Pearson's correlation. For all cases, values of $p<0.05$ will be considered statistically significant.

\section{Results}

Effects of the treatment with Isoflavones and haloperidol on locomotor activity of rats

Haloperidol markedly decreased the number of crossing $[F(3,28)=4,12, p<0,05$; Fig. 1] in the open field test after 28 days of treatment that was reversed by the co-treatment with isoflavones $(p<0,05)$. The treatment with isoflavones alone did not alter the number of crossings.

Effects of isoflavones treatment on haloperidol-induced orofacial dyskinesia

To evaluate the effect of the isoflavones treatment to reducing movement disorders induced by haloperidol, the number of VCM at 29 day was quantified for each animal. The treatment with haloperidol increased the number of VCM when compared to the control group $[F(3,28)=8,63, p<0.001$; Fig. 2]. Cotreatment with Isoflavones was able to reduce VCM in rats $(p<0,01)$. No difference was observed between the control and isoflavones groups.

Effects of Isoflavones in the Levels of Cytokines in the Striatum of rats with haloperidol-induced orofacial dyskinesia

Haloperidol treatment caused significant increase in the levels of pro-inflammatory cytokines IL-1 $\beta$ ( $F[3$, $28]=25.13, p<0,001), \operatorname{TNF}-a(F([3,28]=12.15, p<0,001)$ and IL-6 $(F[3,28]=7.05, p<0,01)$ into the striatum of rats when compared to the control group. However, co-treatment with isofavones was able to reduce the levels of cytokines IL-1 $\beta(p<0,001)$ and TNF- $a(p<0,01)$ in relation to haloperidol group, but not the production of IL-6. In addition, no changes in cytokine levels were observed in the group that received only isoflavones compared to the control group.

\section{Correlation Analysis}

Once the animals treated with haloperidol developed the VCM, we decided to evaluate by correlation analysis if the increase in the levels of pro-inflammatory cytokines are closely related with the intensity of the VCM. Significant correlations were found between VCM and the levels of pro-inflammatory cytokines IL-1 $\beta$ ( $r=0.4677$ and $p=0.0069$, Fig. $4 \mathrm{a})$ and TNF- $\mathrm{a}(r=0.4501$ and $p=0.0097$, Fig. $4 \mathrm{~b})$ in striatum of rats. However, no correlation was observed between VCM and IL-6 (Fig. 4c).

\section{Discussion}

First generation antipsychotics, such as haloperidol, act predominantly blocking D2 type dopaminergic receptors, thus reducing the positive symptoms of the disease (Stahl 2014). However, dopaminergic 
pathway antagonism, such as the nigrostriatal pathway, ends up generating adverse effects, which can be progressive and disabling, such as TD, thus compromising the quality of life of patients who need this medication (Moreno et al. 2004).

This study aimed to investigate the possible protective effect of isoflavones against involuntary movements induced by haloperidol in rats and the role of proinflammatory cytokines in this process. In clinical practice, treatment of extrapyramidal side effects (akathisia, tremor, parkinsonian stiffness, bradykinesia and TD) associated with the use of antipsychotics is generally performed with anticholinergic drugs such as biperiden (Reynoso et al. 2012; Valencia et al. 2012). However, these medications causing anticholinergic side effects (tachycardia, mydriasis, dryness of the mucous membranes and urinary retention), and there is some evidence that anticholinergic medications can increase the positive symptoms of schizophrenia (Ocaña-Zuritaet et al. 2016). According to Egan et al. (1996), anticholinergic drugs do not suppress late VCM.

In this context, natural compounds are used in the search for minimizing the adverse effects of drugs or as adjuvant treatments for diseases, and isoflavones, which are phenolic compounds found mainly in soybeans and are widely described in the literature for having several biological activities beneficial to the organism (Kawakami et al. 2004). Thus, we decided to evaluate its possible protective effect against the VCM induced by haloperidol in rats, a marker of OD in an animal model. After 28 days of treatment where the rats received isoflavones and/or haloperidol, the animals were subjected to the open field test and locomotion was assessed. Reduced locomotion in animals treated with haloperidol is already expected since it is known that blockade of dopamine D2 receptors and reduction of dopaminergic pathway function in nucleus accumbens led to suppression of locomotion and sedation (Kelley et al. 1989; Salamone et al. 2008). However, surprisingly co-treatment with isoflavones restored locomotor activity when compared to the control group.

Estrogens also have been shown to significantly affect mono-aminergic neurotransmitter pathways in the brain, and the agonism of estrogen receptors can up-regulated levels of neurotransmitters such as dopamine, serotonin and norepinephrine (Long et al. 2019). In addition, isoflavones have a similar molecular weight and structure to 17- $\beta$ estradiol (E2), therefore the effects on rodent physiology and behavior may be a result of estrogen-dependent signaling pathways due to interaction with estrogen receptors (ERs) $a$ and $\beta$ (Morito et al. 2001; Cederroth and Nef, 2009). In view of this, we can hypothesize that co-treatment with isoflavones reversed the hypolocomotion caused by treatment with haloperidol by stimulating the release of dopamine through its agonism in estrogen receptors. Another hypothesis to explain the reversal of hypolocomotion observed by co-treatment with isoflavones, is that these phytoestrogens are capable of inhibiting the activity of the monoamine oxidase isoforms (Da Silva Schmitz et al. 2019), thus being able to modulate the amount of monoamines and restore locomotor activity.

Another important finding in this study was that the administration of $80 \mathrm{mg} / \mathrm{kg}$ of isoflavone powder per gavage for 28 days was able to reduce the number of VCM in animals treated with haloperidol. A 
hypothesis that may explain the onset of VCM is that the prolonged treatment with antipsychotics induces the production of proinflammatory mediators causing a neuroinflammation (Bishnoi et al. 2008; Peroza et al. 2016). In a previous study, we showed that rats treated with antipsychotics (haloperidol and risperidone) had high levels of pro-inflammatory cytokines [IL-1 $\beta$, IL-6, TNF-a, interferon- $\gamma$ (IFN- $\gamma$ ) and reduced levels of anti-inflammatory cytokine IL-10] (Peroza et al. 2016). In the study, when the animals were treated with isoflavones, it was observed a significant reduction in the levels of IL-1 $\beta$ and TNF-a, but not IL-6 levels induced in response to haloperidol. These results evidenced that treatment with isoflavones can have an immunomodulatory effect on the central nervous system These results evidenced an immunomodulatory effect in the nervous system induced by the treatment with isoflavones. In addition, the increase in pro-inflammatory cytokines induced by haloperidol was closely linked to the induction of VCM.

Other studies have also shown the anti-inflammatory effect of isoflavones in the nervous system. The effect of isoflavones in the improvement of inflammation induced by carrageenan by inhibiting the NF-KB pathway in mice and in the reduction of inflammatory cytokine levels is already known, as well as the expression of the p65 subunit in the brain of rats treated with $\beta$-amyloid peptide (A $\beta$ ) (Ding et al. 2011). Another study showed that rats that received soy isoflavones $(80 \mathrm{mg} / \mathrm{kg})$ for 14 days, reduced the high levels of IL-1 $\beta$, TNFa, cyclooxygenase-2 (COX-2) and TNF - $\alpha$ in the brain treated with an intracerebroventricular injection of a single dose of colchicine $(7.5 \mu \mathrm{g})$, a rat model of Alzheimer's disease (Essawy et al. 2019).

The cytotoxicity induced by the treatment with haloperidol has been associated with the appearance of extrapyramidal symptoms (Subramanyam et al. 2001). Moreover, an in vitro treatment with haloperidol $(10 \mu \mathrm{M}, 50 \mu \mathrm{M}, 100 \mu \mathrm{M})$ in human dopaminergic neuroblastoma (SH-SY5Y) demonstrated cytotoxic effects in a dose dependent manner after $24 \mathrm{~h}$ of incubation (Yang and Lung 2011). In this context, a study published by Bains \& Roberts (2016) reported that the pre-treatment with 17 $\beta$-estradiol indirectly protects dopaminergic neurons by a mechanism that involves ER-alpha $(\mathrm{ERa})$-mediated PI3K signaling in astrocytes and subsequent neuroprotection of dopaminergic neurons against MPP + induced toxicity. Thus, knowing that isoflavones have a similar molecular weight and structure to $17 \beta$-estradiol and the ability to bind to estrogen receptors (Meza et al. 2015), they could also exert a neuroprotective mechanism against cytotoxicity caused by treatment with haloperidol, thus promoting the reduction of VCM induced by haloperidol found in this study.

\section{Conclusion}

Based on the findings of this study, we can conclude that the isoflavone powder was able to protect against the VCM induced by haloperidol, as well as to restore the locomotor activity of the animals. In addition, it was observed an increase in the levels of proinflammatory cytokine (IL-1 $\beta$, TNF- $\alpha$ and IL-6) in the striatum of rats treated by haloperidol and the co-treatment with isoflavones was able to reduce the production of IL-1 $\beta$ and TNF-a, but not IL-6. Furthermore, it was found positive correlations between IL-1 $\beta$ and TNF-a production and VCM numbers, suggesting that these cytokines can contribute to the 
development of movements disorders such as TD and that isoflavones present an anti-inflammatory and protective effect against the onset of VCM

However, further studies are needed to prove if the neuroprotective effect of these phytoestrogens occurs through the modulation of the content of neurotransmitters due to its anti-inflammatory capacity.

\section{Declarations}

\section{ETHICAL STATEMENT:}

Ethics approval and consent to participate: All applicable international, national, and/or institutional guidelines for the care and use of animals were followed. The experimental protocol was approved by the Animal Use Ethics Commission (CEUA) of the Franciscan University (UFN), under number 05/2017.

Consent for publication: Not Applicable.

Availability of data and materials: Not Applicable.

Competing interests: Authors declare that they do not hold any conflict of interest.

Funding: There was no funding for this study.

Authors' contributions: NFM and LRP: development of experiments, data analysis, and writing manuscript. ISS, VBL, LFS and CRB: animal behavioral analysis and data analysis. GPD and PRTR: cytokine analysis and data analysis. All authors edited and approved the final version of the manuscript.

Acknowledgements: We acknowledge the Franciscan University for the scholarship of scientific initiation (PIBIC- UFN) of the student Izaviany Schmitz da Silva. GPD is supported by postdoctoral fellowship from CAPES (PNPD/CAPES). CRB and PRTR are grateful to CNPq for the PQ productivity scholarship.

\section{References}

1. Amato D, Beasleyb CL, Hahn M, Vernon A (2016) Neuroadaptations to antipsychotic drugs: insights from pre-clinical and human post-mortem studies. Neurosci Biobehav 15:1-19

2. Bains $M$, Roberts JL (2016) Estrogen protects against dopamine neuron toxicity in primary mesencephalic cultures through an indirect P13K/Akt mediated astrocyte pathway. Neurosci Lett 
610:79-85. doi:10.1016/j.neulet.2015.10.054

3. Bhugra D (2005) The global prevalence of schizophrenia. PLoS Med 2:e151

4. Bishnoi M, Chopra K, Kulkarni SK (2008) Activation of striatal inflammatory mediators and caspase3 is central to haloperidol-induced orofacial dyskinesia. Eur J Pharmacol 590:241-245

5. Broadhurst PL (1960) The place of animal psychology in the development of psychosomatic research. European Conference on Psychosom Res. Karger Publishers. 63:69

6. Brown MJ, Sharma P, Bennett PN (2012) Clin Pharmacol: Elsevier Health Sciences

7. Burger $\mathrm{M}$ et al (2004) Effects of age on reserpine-induced orofacial dyskinesia and possible protection of diphenyl diselenide. Brain Res Bull 64:339-345

8. Casey DE (1993) Serotonergic and dopaminergic aspects of neuroleptic-induced extrapyramidal syndromes in nonhuman primates. Psychopharmacol 112:S55-S59

9. Cederroth CR, Nef S (2009) Soy, phytoestrogens and metabolism: a review. Mol Cell Endocrinol 304:30-42

10. Cook NC, Samman S (1996) Flavonoids-chemistry, metabolism, cardioprotective effects, and dietary sources. J Nutr Biochem 7:66-76

11. Da Silva Schmitz I et al (2019) Isoflavones prevent oxidative stress and inhibit the activity of the enzyme monoamine oxidase in vitro. Mol Biol Rep 46:2285-2292

12. Ding BJ et al (2011) Soybean isoflavone alleviates $\beta$-amyloid 1-42 induced inflammatory response to improve learning and memory ability by down regulation of Toll-like receptor 4 expression and nuclear factor-KB activity in rats. Int J Dev Neurosci 29:537-542

13. Dixon RA (2004) Phytoestrogens. Annu Rev Plant Biol 55:225-261

14. Egan MF, Hurd Y, Ferguson J, Bachus SE, Hamid EH, Hyde TM (1996) Pharmacological and neurochemical differences between acute and tardive vacuous chewing movements induced by haloperidol. Psychopharmacol 127:337-345. doi:10.1007/s002130050095

15. Essawy AE, Abdou HM, Ibrahim HM, Bouthahab NM (2019) Soybean isoflavone ameliorates cognitive impairment, neuroinflammation, and amyloid $\beta$ accumulation in a rat model of Alzheimer's disease. Environ Sci Pollut Res Int 26:26060-26070. doi:10.1007/s11356-019-05862-z

16. Fachinetto $\mathrm{R}$ et al (2007) Valeriana officinalis does not alter the orofacial dyskinesia induced by haloperidol in rats: role of dopamine transporter. Prog Neuropsychopharmacol Biol Psychiatry 31:1478-1486

17. Frank-Cannon TC, Alto LT, McAlpine FE, Tansey MG (2009) Does neuroinflammation fan the flame in neurodegenerative diseases? Mol Neurodegener 4:47

18. Glass CK, Saijo K, Winner B, Marchetto MC, Gage FH (2010) Mechanisms underlying inflammation in neurodegeneration. Cell 140:918-934

19. Glazer WM (2000) Expected incidence of tardive dyskinesia associated with atypical antipsychotics. J Clin Psychiatry 4:21-26 
20. ljaz S, Bolea B, Davies S, Savović J, Richards A, Sullivan S, Moran P (2018) Antipsychotic polypharmacy and metabolic syndrome in schizophrenia: a review of systematic reviews. BMC Psychiatry 18:275

21. Kawakami $Y$ et al (2004) Regulative actions of dietary soy isoflavone on biological antioxidative system and lipid metabolism in rats. J Agric Food Chem 52:1764-1768

22. Kelley AE, Bakshi VP, Delfs JM, Lang CG (1989) Cholinergic stimulation of the ventrolateral striatum elicits mouth movements in rats: pharmacological and regional specificity. Psychopharmacol (Berl) 99:542-549

23. Liu YQ, Xin TR, Liang JJ, Wang WM, Zhang YY (2010) Memory Performance, Brain Excitatory Amino Acid and Acetylcholinesterase Activity of Chronically Aluminum Exposed Mice in Response to Soy Isoflavones Treatment. Phytother Res 24:1451-1456

24. Liu H et al (2012) Lower serum interleukin-2 levels in schizophrenic patients with tardive dyskinesia. Psychiatry Res 198:329-331

25. Long T, Yao JK, Li J et al (2019) Estradiol and selective estrogen receptor agonists differentially affect brain monoamines and amino acids levels in transitional and surgical menopausal rat models. Mol Cell Endocrinol 496:110533. doi:10.1016/j.mce.2019.110533

26. Lohr JB (1991) Oxygen radicals and neuropsychiatric illness. Some speculations. Arch Gen Psychiatry 48:1097-1106

27. Moreno RA et al (2004) Anticonvulsivantes e antipsicóticos no tratamento de transtorno bipolar. Psiquiatr 26:37-43

28. Morito K et al (2001) Interaction of phytoestrogens with estrogen receptors alpha and beta. Biol Pharm Bull 24:351-356

29. Nardi AE, Quevedo J, Da Silva AG (2015) Esquizofrenia: teoria e clínica. Artmed Editora

30. Ocaña-Zurita MC, Juárez-Rojop IE, Genis A et al (2016) Potential drug-drug interaction in Mexican patients with schizophrenia. Int J Psychiatry Clin Pract 20:249-253. doi:10.1080/13651501.2016.1213854

31. Peroza LR et al (2013) Bauhinia forficata prevents vacuous chewing movements induced by haloperidol in rats and has antioxidant potential in vitro. Neurochem Res 38:789-796

32. Peroza LR et al (2016) Alteration of Cytokines Levels in the Striatum of Rats: Possible Participation in Vacuous Chewing Movements Induced by Antipsycotics. Neurochem Res 41:2481-2489

33. Prieto P, Pineda M, Aguilar M (1999) Spectrophotometric quantitation of antioxidant capacity through the formation of a phosphomolybdenum complex: specific application to the determination of vitamin E. Anal Biochem 269:337-341

34. Reynoso SF, Davalos RM, Garcia RR, Agraz FP (2012) Estigma y apego al tratamiento psiqui_atrico en los trastornos mentales severos y persistentes. Rev Latinoam Psiquiatría 11:82

35. Salamone JD, Ishiwari K, Betz AJ, Farrar AM, Mingote SM, Font L, Hockemeyer J, Muller CE, Correa M (2008) Dopamine/ adenosine interactions related to locomotion and tremor in animal models: 
possible relevance to parkinsonism. Parkinsonism Relat Disord 2:130-134

36. Smith JA, Das A, Ray SK, Banik NL (2012) Role of pro-inflammatory cytokines released from microglia in neurodegenerative diseases. Brain Res Bull 87:10-20

37. Stahl SM (2014) Psicofarmacologia: bases neurocientíficas e aplicações práticas, 4. edn. Guanabara Koogan, Rio de Janeiro

38. Subramanyam B, Woolf T, Castagnoli NJ (1991) Studies on the in vitro conversion of haloperidol to a potentially neurotoxic pyridinium metabolite. Chem Res Toxicol 4:123-128.

doi:10.1021/tx00019a017

39. Tsai $\mathrm{G}$ et al (1998) Markers of glutamatergic neurotransmission and oxidative stress associated with tardive dyskinesia. Am J Psychiatry 155:1207-1213

40. Valencia M, Diaz A, Juarez F (2012) Integration of pharmacological and psychosocial treatment for schizophrenia in mexico: The case of a developing country proposal. Edited by Farid Badria.41

41. Wei H, Wei L, Frenkel K, Bowen R, Barnes S (1993) Inhibition of tumor promoter-induced hydrogen peroxide formation in vitro and in vivo by genistein. Nutr Cancer 20:1-12

42. Witter DP, Holbert RC, Suryadevara U (2017) Pharmacotherapy for the treatment of tardive dyskinesia in schizophrenia patients. Expert Opin Pharmacother 18:965-972

43. Yang M, Lung F (2011) Neuroprotection of paliperidone on SH-SY5Y cells against $\beta$-amyloid peptide25-35, N-methyl-4-phenylpyridinium ion, and hydrogen peroxide-induced cell death. Psychopharmacol 217:397-410. https://doi.org/10.1007/s00213-011-2291-7

\section{Figures}


Control

Isoflavones

$\$ \infty \times$ Haloperidol

Haloperidol + Isoflavones

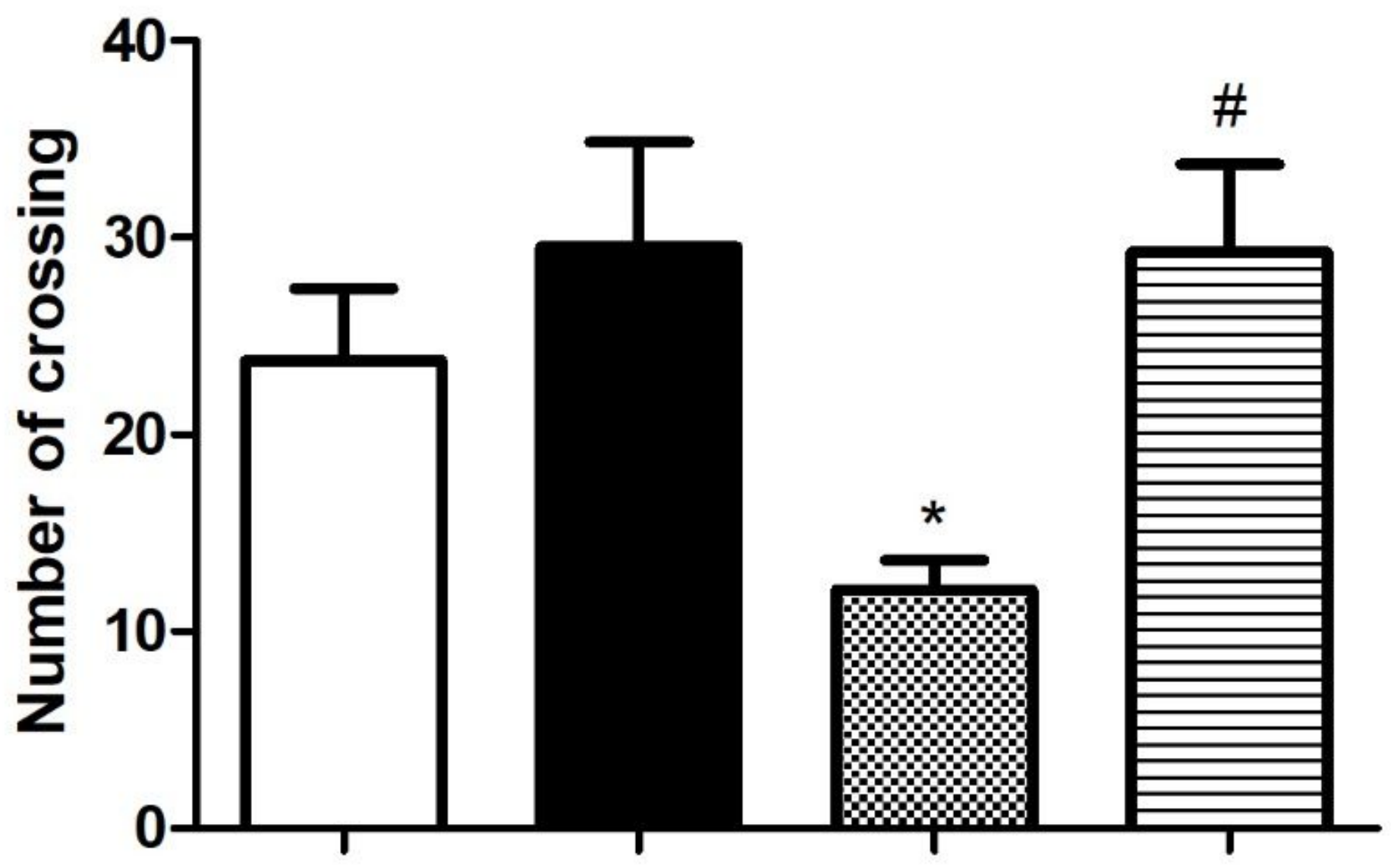

Figure 1

Locomotor activity of rats treated with haloperidol and /or isoflavones at the end of treatment. Values are presented as mean + SEM . One-way ANOVA followed by Newman-Keuls test, ${ }^{*} p<0.05$ vs control group. $\# p<0.05$ vs haloperidol group. Number of animals per group $=8$. 


\section{Control}

Isoflavones

$\infty \infty \infty \times \infty$ Haloperidol

Ealoperidol + Isoflavones

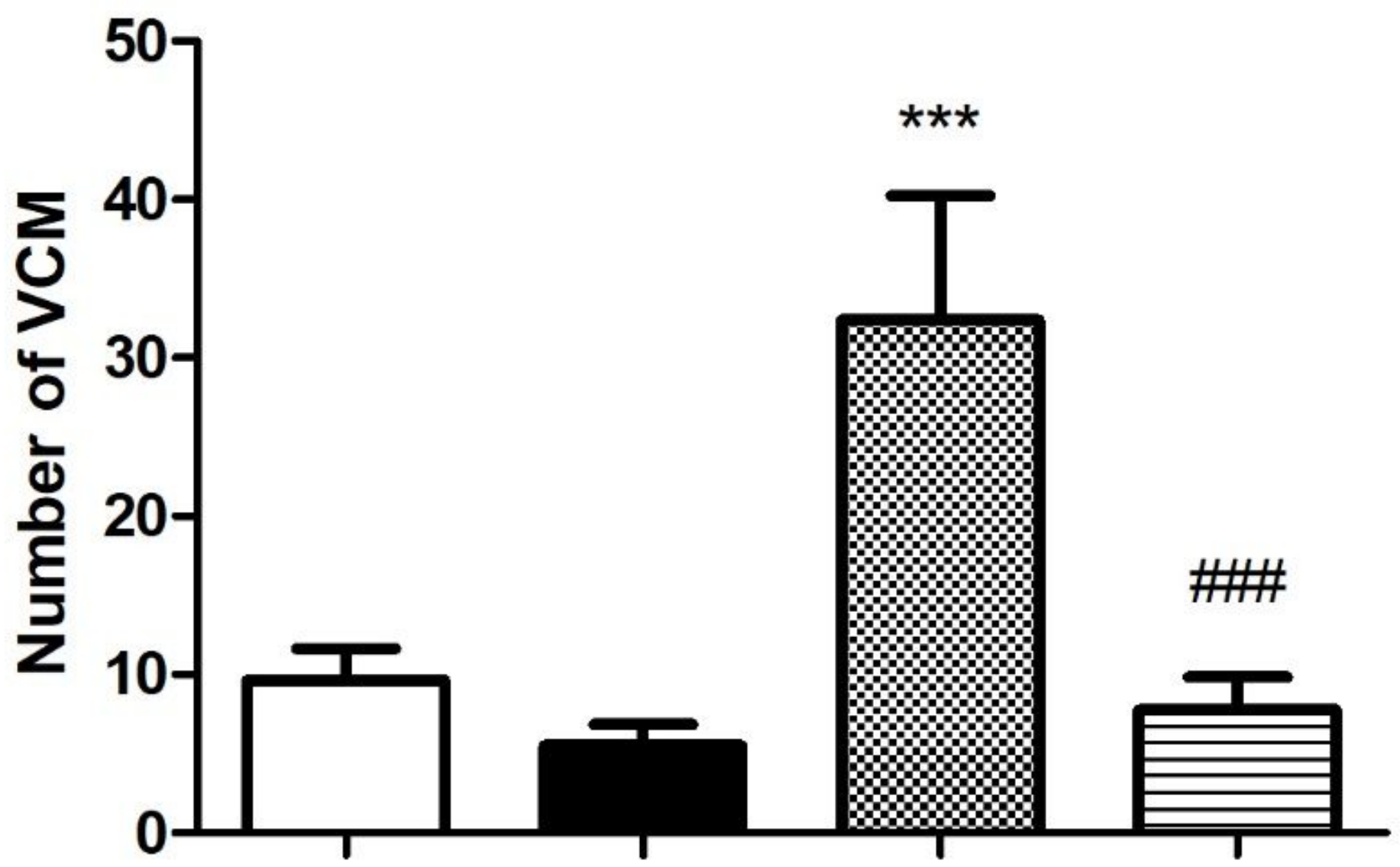

Figure 2

Effect of the treatment of haloperidol and / or isoflavones on VCM. The number of VCM in rats inoculated with haloperidol and trated with isoflavones was determined $24 \mathrm{~h}$ the last dose of isoflavone .

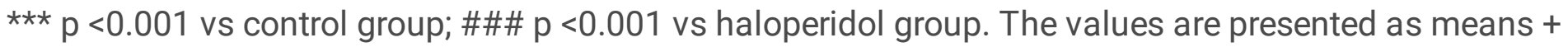
SEM. One-way ANOVA followed by Newman-Keuls test. Number of animals per group $=8$. 
A

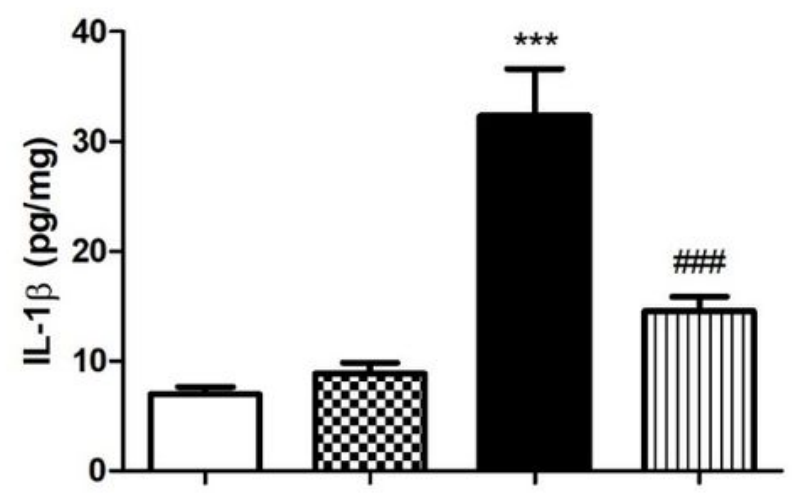

B

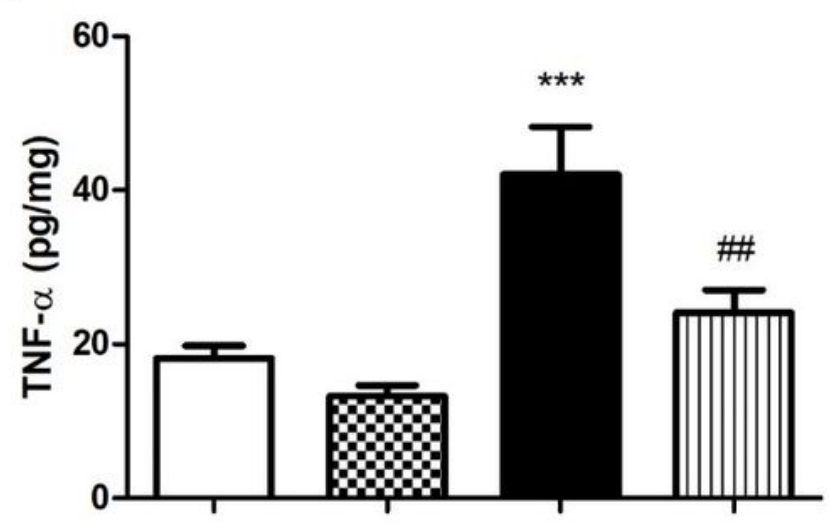

C

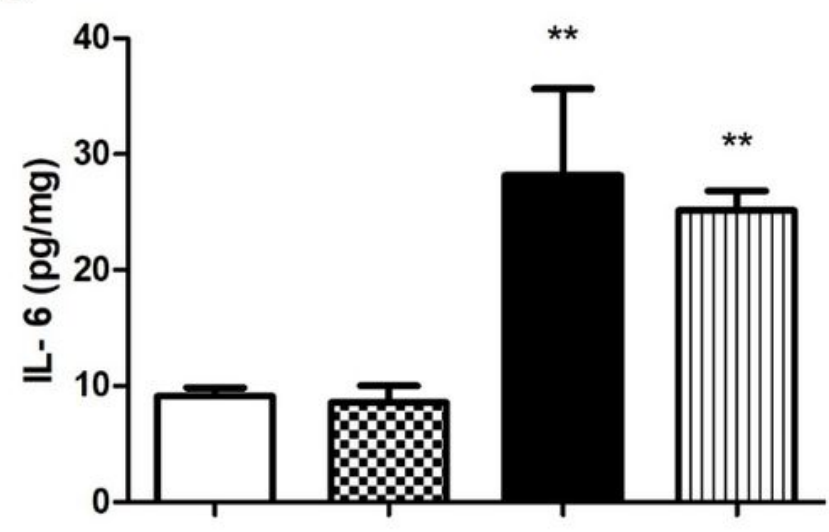

Figure 3

Effects of isoflavones and/or haloperidol in the levels of proinflammatory cytokines: IL-1 $\beta$ (a), TNF-a (b) and IL-6 (c) in the striatum of rats. Data are presented as mean \pm SEM. One-way ANOVA followed by Newman-Keuls test. ${ }^{* *} p<0.001$ vs control; ${ }^{* *} p<0.01$ vs control; \#\#\# $p<0.001$ vs haloperidol; \#\# $p<$ 0.01 vs haloperidol. 


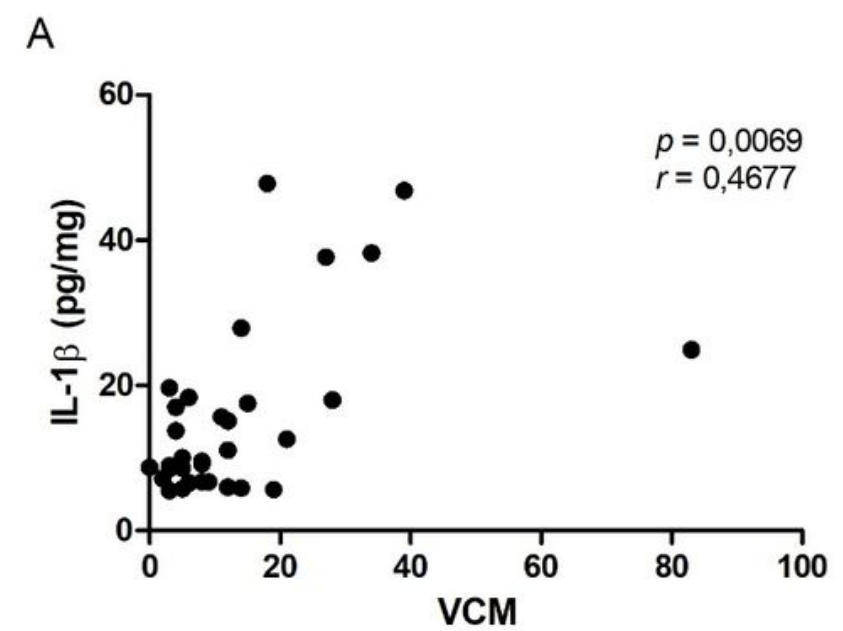

B

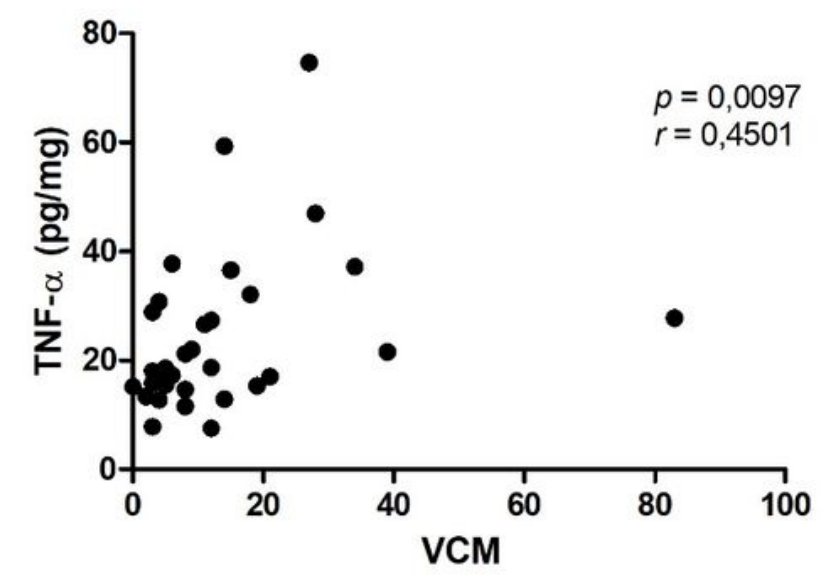

C

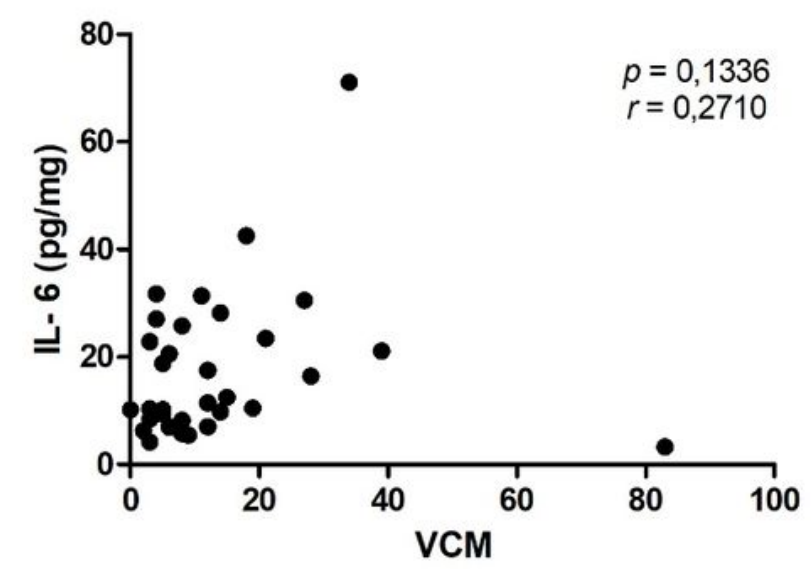

Figure 4

Correlation between the values of VCM and cytokine levels in the striatum of rats treated with isoflavones and/or haloperidol. Values of $r$ and $p$ are showed for each cytokine (IL-1 $\beta$, TNF- $a$ and IL-6). 